\title{
Comparison of clinical and radiological results of fixation methods with retrograde intramedullary Kirschner wire and plate-screw in extra-articular metacarpal fractures
}

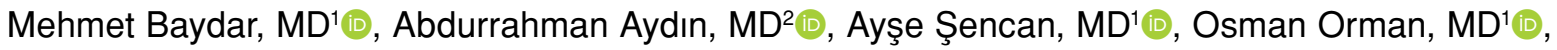 \\ Serkan Aykut, $\mathrm{MD}^{2}$ (D) Kahraman Öztürk, $\mathrm{MD}^{1}{ }^{1}$
}

1Department of Orthopedics and Traumatology, Division of Hand Surgery Clinic, University of Health Sciences, Metin Sabancı Bone Diseases Training and Research Hospital, Istanbul, Turkey

${ }^{2}$ Department of Orthopedics and Traumatology, University of Health Sciences, Metin Sabancı Bone Diseases Training and Research Hospital, Istanbul, Turkey

Metacarpal fractures are among the most common injuries evaluated by hand surgeons and constitute $30 \%$ of all hand fractures ${ }^{[1]}$ Metacarpal shaft fractures can result from axial loading, torsion or a direct blow, and they typically present as transverse, oblique, or comminuted fractures. ${ }^{[2,3]}$

Many surgical techniques have been described for metacarpal bone fractures and include percutaneous and limited open antegrade, retrograde, or transmetacarpal Kirschner-wire (K-wire) fixations and screw and plate-screw (PS) fixations. ${ }^{[4]}$ Each technique has advantages and disadvantages, and no

Received: February 19, 2021

Accepted: April 04, 2021

Published online: June 11, 2021

Correspondence: Mehmet Baydar, MD. Metin Sabancl

Baltalimanı Kemik Hastalıkları Eğitim ve Araştırma Hastanesi,

El Cerrahisi Bölümü, 34470 Sarıyer, İstanbul, Türkiye.

E-mail: drmehmetbaydar@hotmail.com

Doi: $10.52312 /$ jdrs.2021.40

Citation: Baydar M, Aydın A, Sencan A, Orman O, Aykut S, Öztürk $\mathrm{K}$. Comparison of clinical and radiological results of fixation methods with retrograde intramedullary Kirschner wire and plate-screw in extra-articular metacarpal fractures. Jt Dis Relat Surg 2021;32(2):397-405.

(O2021 All right reserved by the Turkish Joint Diseases Foundation

This is an open access article under the terms of the Creative Commons Attribution-NonCommercial License, which permits use, distribution and reproduction in any medium, provided the original work is properly cited and is not used for commercial purposes (http://creativecommons.org/licenses/by-nc/4.0/).

\section{ABSTRACT}

Objectives: In this study, we aimed to compare clinical and radiographic outcomes of retrograde intramedullary Kirschner-wire (K-wire) fixation with those of plate-screw (PS) fixation.

Patients and methods: A total of 98 metacarpal shaft fractures in 75 patients $(65$ males, 10 females; mean age: $31.2 \pm 10.9$ years; range, 16 to 65 years) were included between January 2011 and December 2017. The total joint active range of motion (AROM) and grip strength of the healthy and broken hands were evaluated. The Visual Analog Scale (VAS) and Quick Disabilities of the Arm, Shoulder, and Hand (QuickDASH) scores were recorded. We compared surgery duration, number of fluoroscopy images, and cost-effectiveness for each technique.

Results: The overall mean follow-up was 21.9 (range, 12 to 56) months. At the last follow-up, total joint AROM ( $\mathrm{p}=0.072)$, VAS score $(\mathrm{p}=0.298)$, QuickDASH score $(\mathrm{p}=0.132)$, and hand grip strength $(\mathrm{p}=0.947)$ were similar between the groups. Radiological union occurred in the PS and K-wire groups in a mean of 5.84 (range, 3 to 8 ) and 4.46 (range, 3 to 20 ) weeks, respectively $(\mathrm{p}=0.173$ ). A significant difference was found in surgery duration $(\mathrm{p}=0.021)$ and number of fluoroscopy images $(\mathrm{p}<0.05)$ between the PS and K-wire groups. Two wound complications were observed in the PS group and one with K-wires.

Conclusion: Retrograde intramedullary K-wire fixation has certain advantages such as being less invasive and more accessible with shorter operation time, compared to PS fixation. Similar radiological and clinical scores can be obtained in patients undergoing retrograde intramedullary K-wire fixation or PS fixation.

Keywords: Hand trauma, intramedullary fixation, Kirschner wire, metacarpal fracture, plate-screw fixation.

consensus exists for optimum treatment. Stability of the fracture and sustainability of that stability are the main treatment determinants. ${ }^{[5,6]}$ The K-wire fixation can be an option for transverse fractures, PS fixation 
can be preferred for comminuted fractures, and both can be applied in oblique and spiral fractures. ${ }^{[5]}$ Applying the principle of biological and rigid fixation that allows for early mobilization is essential for an excellent functional outcome. The PS fixation seems to be advantageous in that its rigidity allows for early rehabilitation; ${ }^{[6]}$ however, it may have adverse effects on fracture healing, joint stiffness, plate loosening or breakage, tendon rupture, and complex regional pain syndrome. ${ }^{[7,8]}$

In the literature, antegrade or retrograde intramedullary K-wire fixation has been compared with PS fixation for metacarpal shaft fractures, and instability and eventual malrotation, shortening of the fracture, and penetration to the metacarpophalangeal (MCP) joint have been reported. ${ }^{[9,10]}$ To avoid these disadvantages, in patients diagnosed with extraarticular metacarpal shaft fracture, K-wires can be sent from the dorsal of the collateral ligaments and the cartilage-bone border within the joint, thereby, preventing postoperative joint stiffness.

In the treatment of extra-articular metacarpal fractures, antegrade or retrograde K-wire fixation can be used. In this study, we aimed to compare clinical and radiographic outcomes of retrograde intramedullary K-wire fixation with those of PS fixation.

\section{PATIENTS AND METHODS}

This single-center, retrospective study was conducted at Baltalimanı Bone Diseases Training and Research Hospital between January 2011 and December 2017. A total of 98 metacarpal shaft fractures in 75 patients (65 males, 10 females;

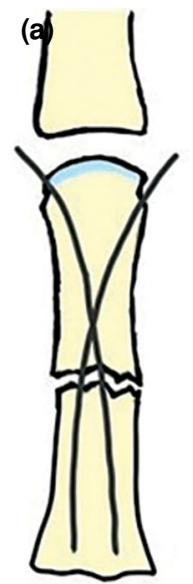

(b)

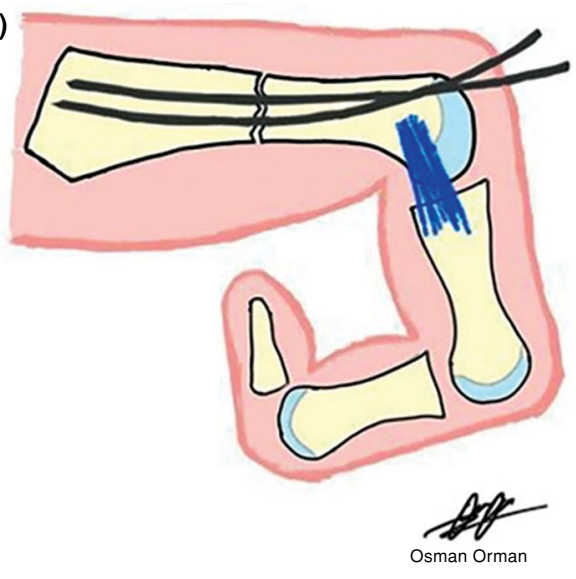

FIGURE 1. Illustration shows the entry points of Kirschner wires in (a) coronal and (b) sagittal planes. mean age: $31.2 \pm 10.9$ years; range, 16 to 65 years) were included. The patients were treated surgically with either retrograde K-wire ( $\mathrm{n}=37,47$ metacarpal fractures) or PS fixation $(n=38,51$ metacarpal fractures). We excluded patients with an intraarticular fracture, thumb fractures, or pathological metacarpal fractures, those with a less than one year of follow-up period, and patients with closed epiphysis. A written informed consent was obtained from each patient. The study protocol was approved by the Baltalimanı Bone Diseases Training and Research Hospital Ethics Committee (Approval Date/No: 26.11.2020/65-450). The study was conducted in accordance with the principles of the Declaration of Helsinki.

\section{Surgical technique}

All patients were operated in the supine position, under infraclavicular block anesthesia, and with a tourniquet application. Operations were performed by two surgeons with broad experience in hand surgery.
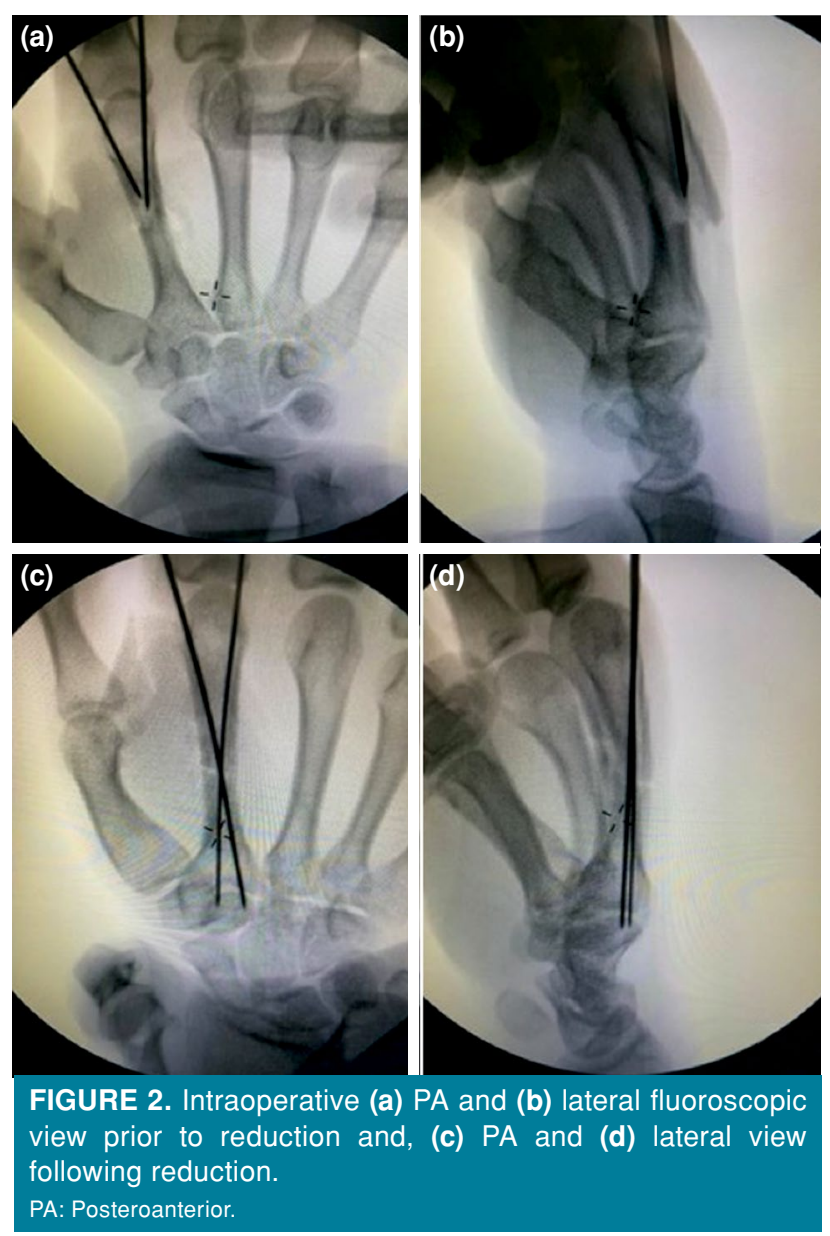


\begin{tabular}{|c|c|c|c|c|c|}
\hline \multicolumn{6}{|c|}{$\begin{array}{l}\text { TABLE I } \\
\text { of the group fixed with retrograde intra-medullary K-wire and PS }\end{array}$} \\
\hline \multicolumn{6}{|l|}{ K-wire } \\
\hline & $2^{\text {nd }}$ metacarpal & $3^{\text {rd }}$ metacarpal & $4^{\text {th }}$ metacarpal & $5^{\text {th }}$ metacarpal & Total \\
\hline Oblique/spiral & 1 & - & 6 & 13 & 20 \\
\hline Transverse & 5 & 1 & 8 & 9 & 23 \\
\hline Comminuted & - & 1 & - & 3 & 4 \\
\hline Total & 6 & 2 & 14 & 25 & 47 \\
\hline \multicolumn{6}{|l|}{ Plate-screw } \\
\hline & $2^{\text {nd }}$ metacarpal & $3^{\text {rd }}$ metacarpal & $4^{\text {th }}$ metacarpal & $5^{\text {th }}$ metacarpal & Total \\
\hline Oblique/spiral & 11 & 11 & 11 & 4 & 37 \\
\hline Transverse & 3 & 1 & 2 & 1 & 7 \\
\hline Comminuted & 1 & 3 & 1 & 2 & 7 \\
\hline Total & 15 & 15 & 14 & 7 & 51 \\
\hline
\end{tabular}

For the PS fixation group, a longitudinal dorsal approach was used and a low-profile 2.0 to $2.4-\mathrm{mm}$ titanium miniplate was applied (DePuy Synthes, PA, USA) on the dorsoulnar aspect for fracture fixation. At least two screws on each side of the fracture line passing at least four cortices were used. Interfragmentary screws were applied for long oblique or comminuted fractures whenever required. The periosteum with fascial flap (the fascia covering the dorsal interosseous muscle) was used for plate covering to prevent tendon irritation.

For the K-wire fixation group, the MCP joint was first flexed to $90^{\circ}$ to avoid the wire passing through collateral ligaments. Dorsal to posterior tubercle in the sagittal plane proximal to articular cartilage, two K-wires, one each from the radial and ulnar side, were inserted percutaneously (Figure 1). After checking with fluoroscopy that the K-wires were in the medullary cavity, the fracture was reduced with traction, and the previously placed K-wires were advanced retrogradely by passing through the carpometacarpal (CMC) joint (Figure 2). The K-wires varying between 1.0 and $1.4 \mathrm{~mm}$ were used as suitable for the medullary cavity width. For fractures without successful closed reduction (6 of 47 metacarpal fractures),

\begin{tabular}{|c|c|c|c|c|c|c|}
\hline \multicolumn{7}{|c|}{$\begin{array}{l}\text { TABLE II } \\
\text { Demographic data of patients according to treatment groups }\end{array}$} \\
\hline & \multicolumn{3}{|c|}{ Plate-screw group } & \multicolumn{3}{|c|}{ Kirschner-wire group } \\
\hline & $\mathrm{n}$ & Mean $\pm S D$ & Min-Max & $\mathrm{n}$ & Mean $\pm S D$ & Min-Max \\
\hline Age (year) & & $34.2 \pm 11.1$ & $16-56$ & & $27.8 \pm 97$ & $19-66$ \\
\hline \multicolumn{7}{|l|}{ Sex } \\
\hline Female & 5 & & & 5 & & \\
\hline Male & 33 & & & 32 & & \\
\hline \multicolumn{7}{|l|}{ Fractured hand/dominant hand } \\
\hline Right & $14 / 25$ & & & $17 / 36$ & & \\
\hline Left & $21 / 13$ & & & $12 / 1$ & & \\
\hline \multicolumn{7}{|l|}{ Trauma etiology } \\
\hline Falling & 26 & & & 21 & & \\
\hline Punching & 8 & & & 15 & & \\
\hline Blunt trauma & 12 & & & 4 & & \\
\hline Other (traffic accident, work accident, door) & 5 & & & 7 & & \\
\hline Smokers/nonsmokers & $18 / 20$ & & & $13 / 24$ & & \\
\hline
\end{tabular}


fracture reduction was achieved by making a mini-open longitudinal incision. The K-wires were bent and buried under the skin in all cases. In four comminuted fractures, additional K-wires were used for fixation.

\section{Postoperative care}

All patients were treated with a short-arm splint in intrinsic plus position for seven to 10 days until postoperative edema and pain decreased. After 10 days, the splint was removed, and passive exercises were initiated in the interphalangeal joints and the MCP joint. Active movement was allowed after the initiation of the radiological union at Week 4 . The K-wires were removed at Week 6 under local anesthesia in the outpatient clinic. By the end of the third month, the patients were allowed to participate in contact sports.

\begin{tabular}{|c|c|c|c|c|}
\hline \multicolumn{5}{|c|}{$\begin{array}{l}\text { TABLE III } \\
\text { diological results of PS and K-wire groups }\end{array}$} \\
\hline & Group & $\mathrm{n}$ & Mean & Min-Max \\
\hline \multirow[t]{2}{*}{ Time until operation (day) } & Plate-screw & 51 & 13.31 & $1-35$ \\
\hline & K-wire & 47 & 9.11 & $1-28$ \\
\hline \multirow[t]{2}{*}{ Surgical time } & Plate-screw & 51 & 82.54 & $45-150$ \\
\hline & K-wire & 47 & 58.51 & $25-120$ \\
\hline \multirow[t]{2}{*}{ Follow-up time (month) } & Plate-screw & 51 & 20.9 & $13-45$ \\
\hline & K-wire & 47 & 23.6 & $12-56$ \\
\hline \multirow[t]{2}{*}{ Union time } & Plate-screw & 51 & 5.84 & $3-8$ \\
\hline & K-wire & 47 & 4.46 & $3-20$ \\
\hline \multirow[t]{2}{*}{ AROM } & Plate-screw & 51 & 267.25 & $245-275$ \\
\hline & K-wire & 47 & 258.93 & $250-275$ \\
\hline \multirow[t]{2}{*}{ VAS score } & Plate-screw & 51 & .74 & $0-5$ \\
\hline & K-wire & 47 & 1.14 & $0-4$ \\
\hline \multirow[t]{2}{*}{ Quick DASH score } & Plate-screw & 51 & 5.06 & $0-36.4$ \\
\hline & K-wire & 47 & 7.13 & $0-20.5$ \\
\hline \multirow[t]{2}{*}{ Fractured/healthy hand grip strength (kgW) } & Plate-screw & 51 & $43.41 / 46.50$ & $35-60$ \\
\hline & K-wire & 47 & $43.53 / 44.34$ & $22-58$ \\
\hline \multirow[t]{2}{*}{ Preoperative coronal angulation } & Plate-screw & 51 & 8.69 & $0-55$ \\
\hline & K-wire & 47 & 4.74 & $0-83$ \\
\hline \multirow[t]{2}{*}{ Preoperative sagittal angulation } & Plate-screw & 51 & 12.94 & $0-42$ \\
\hline & K-wire & 47 & 20.65 & $0-76$ \\
\hline \multirow[t]{2}{*}{ Postoperative coronal angulation } & Plate-screw & 51 & 0.8 & $0-4$ \\
\hline & K-wire & 47 & 1.02 & $0-23$ \\
\hline \multirow[t]{2}{*}{ Postoperative sagittal angulation } & Plate-screw & 51 & 1 & $0-5$ \\
\hline & K-wire & 47 & 1.08 & $0-20$ \\
\hline \multirow[t]{2}{*}{ Preoperative shortening (mm) } & Plate-screw & 51 & 5.39 & $0-18$ \\
\hline & K-wire & 47 & 2.29 & $0-10$ \\
\hline \multirow[t]{2}{*}{ Postoperative shortening (mm) } & Plate-screw & 51 & .34 & $0-6$ \\
\hline & K-wire & 47 & .05 & $0-4$ \\
\hline \multirow[t]{2}{*}{ Contracture/tenolysis } & Plate-screw & 51 & 3 & \\
\hline & K-wire & 47 & 1 & \\
\hline \multirow[t]{2}{*}{ Local wound infection } & Plate-screw & 51 & 2 & \\
\hline & K-wire & 47 & 1 & \\
\hline
\end{tabular}




\section{Clinical evaluation}

Table I shows anatomical location and type fractures, and fixation method. Tables II and III show sex, age, time to surgery after admission to the hospital, number of fractures and patients, time in surgery, number of fluoroscopy images, fixation implant costs ( $\$ 150$ for PS and $\$ 4$ for K-wire), follow-up time, complications, functional outcome measures (total joint active range of motion [AROM] scores, the Visual Analog Scale [VAS] scores, and the Quick Disabilities of the Arm, Shoulder, and Hand scale [QuickDASH] scores, and grip strength), and radiographic parameters (pre- and postoperative angulation and shortening, time to union).

Grip strength was measured using a Jamar dynamometer (Asimov Engineering Co., Los Angeles, CA, USA). Serial postoperative radiographs (postoperative Day 1; Weeks 2, 4, and 6; Month 3) for fracture union, implant failure, joint narrowing, arthrosis, and chondrolysis were evaluated. Total joint active range of motion (AROM) with a finger goniometer in the last follow-up visit was assessed.

\section{Statistical analysis}

Statistical analysis was performed using the IBM SPSS version 22.0 software (IBM Corp., Armonk, NY, USA). Data were presented in mean \pm standard deviation (SD), median (min-max) or number and frequency. The Shapiro-Wilk test was used to analyze whether data were normally distributed. The relationship between the treatment modality and total joint AROM, union time, radiological and clinical rotation, and grip strength, as well as the relationship between VAS and QuickDASH were examined using the Mann-Whitney $U$ test. A $p$ value of $<0.05$ was considered statistically significant.

\section{RESULTS}

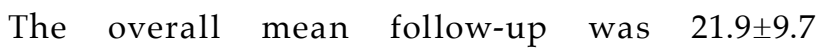
(range, 12 to 56) months. The mean follow-up was 23.6 \pm 11.4 (range, 12 to 56) months in the K-wire group and $20.9 \pm 7.8$ (range, 13 to 45 ) months in the PS group ( $\mathrm{p}=0.06)$ (Table II).

In the preoperative period, in the PS group, the mean angulation of the coronal plane was measured
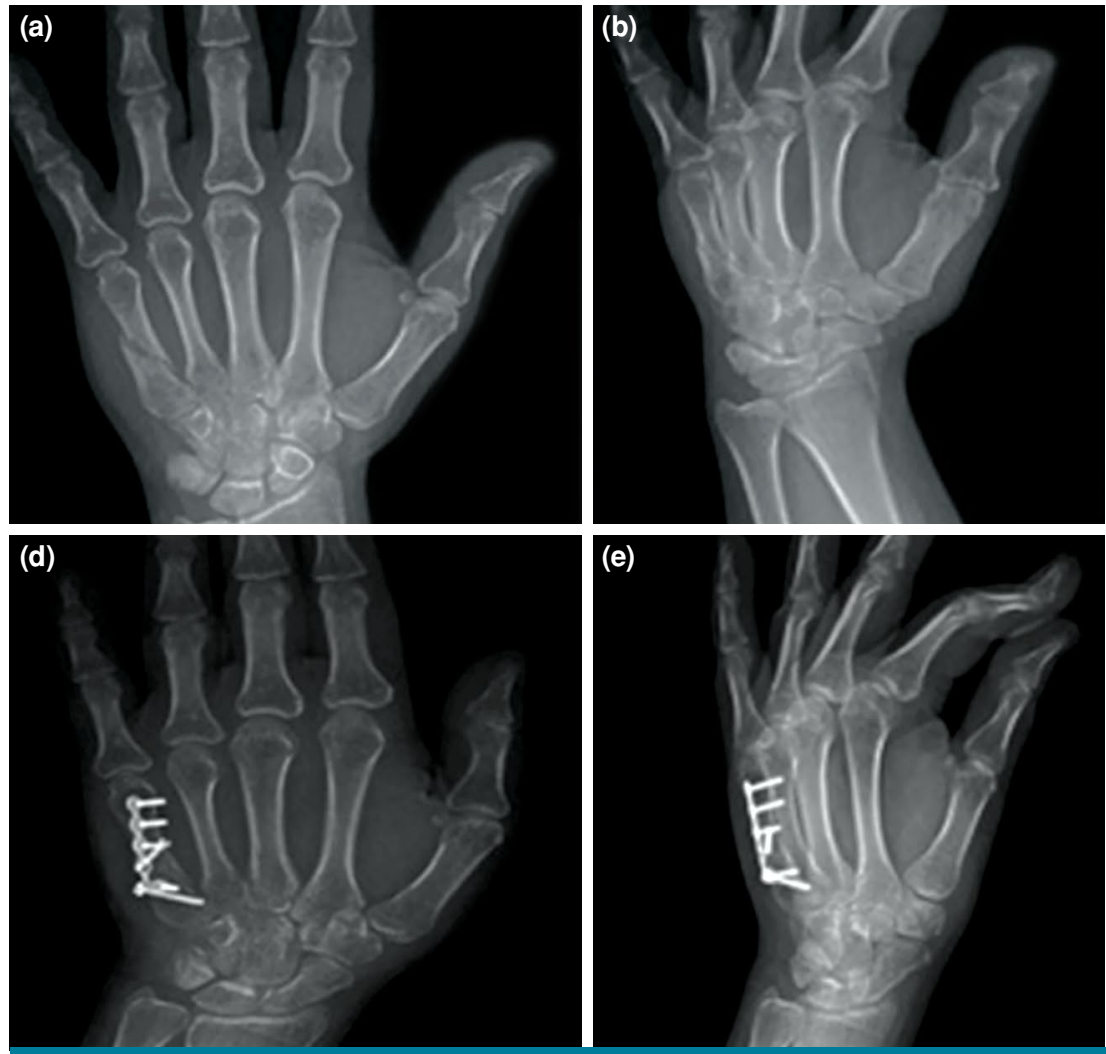

FIGURE 3. Preoperative (a) PA, (a) oblique, and (c) lateral X-ray of a 36 -year-old female patient with an oblique fracture of $5^{\text {th }}$ metacarpal bone. Postoperative $14^{\text {th }}$ month (d) PA, (e) oblique, and (f) lateral X-rays are presented.

PA: Posteroanterior. 
at $8.69 \pm 12.4^{\circ}$ (range, 0 to $55^{\circ}$ ), while the mean angulation in the sagittal plane was measured at $12.94 \pm 14.2^{\circ}$ (range, 0 to $42^{\circ}$ ). In the K-wire group, the mean angulation was $4.7 \pm 3.1^{\circ}$ (range, 0 to $83^{\circ}$ ) in the coronal plane and $20.7 \pm 21.6$ (range, 0 to $76^{\circ}$ ) in the sagittal plane. The mean postoperative angulation was $0.8 \pm 2.1^{\circ}$ (range, 0 to $4^{\circ}$ ) and $1 \pm 2.1^{\circ}$ (range, 0 to $5^{\circ}$ ) in the coronal and sagittal planes, respectively in the PS group. The mean postoperative angulation was $1.02 \pm 3.9^{\circ}$ (range, 0 to $23^{\circ}$ ) and $1.08 \pm 5.9^{\circ}$ (range, 0 to $20^{\circ}$ ) in the coronal and sagittal planes, respectively in the K-wire group (Table III).
In the K-wire group, one patient in the coronal plane and two patients in sagittal plane had an angulation within acceptable limits that did not affect function. There was no statistically significant difference in the mean angulations between the groups (K-wire: $2.3 \pm 6.2$ vs. PS: $1 \pm 3.9, \mathrm{p}=0.022$ ).

The mean preoperative shortening was measured at $5.4 \pm 4.2$ (range, 0 to 18 ) $\mathrm{mm}$ in the PS group and $2.3 \pm 2.3$ (range, 0 to 10 ) $\mathrm{mm}$ in the K-wire group. Postoperative shortening was measured at 0.05 (range, 0 to 4 ) $\mathrm{mm}$ in the PS group and 0.34 (range, 0 to 6) $\mathrm{mm}$ in the K-wire group (Table III).
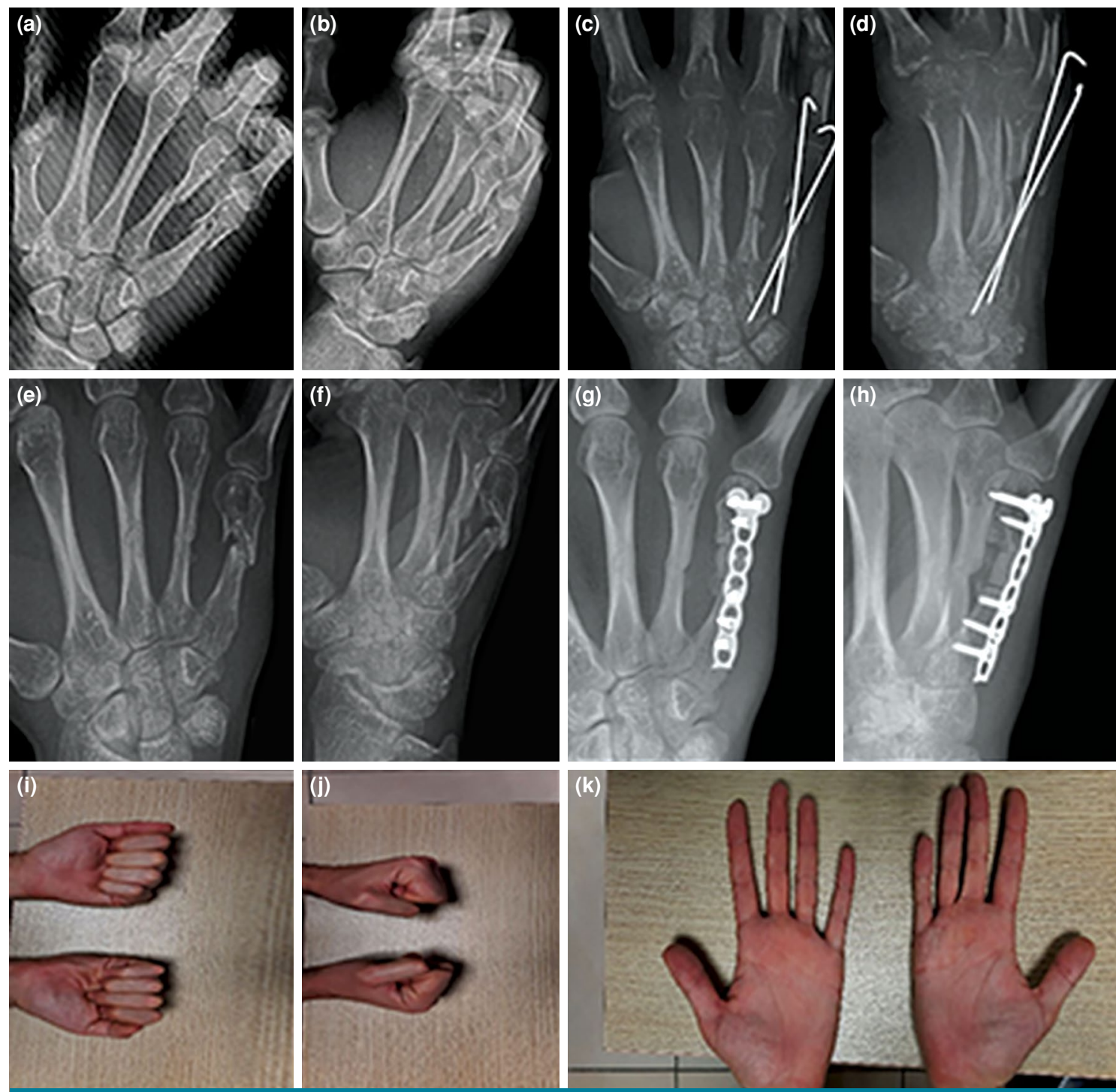

FIGURE 4. Preoperative (a) PA and (b) oblique X-rays showing displacement and shortening of a 24-year-old male patient with $4^{\text {th }}$ and $5^{\text {th }}$ metacarpal fractures in his right hand. (c and d) The Kirschner wires were kept until postoperative third month for the delayed union in the $5^{\text {th }}$ metacarpal bone. (e and $f$ ) At postoperative $5^{\text {th }}$ month, nonunion was significant. ( $g$ and $\mathbf{h}$ ) Revision surgery was performed with autograft and plate-screw. (i-k) Functional pictures of the patient at postoperative third year.

PA: Posteroanterior. 
We observed no displacement, nonunion, angulation, or rotational deformity in the PS group (Figure 3). In the K-wire group, however, two patients had revision surgery due to nonunion, which was revised with autograft and PS (Figure 4), and the other was revised with autograft and K-wire. Three patients in the K-wire group had a $5^{\text {th }}$ metacarpal angulation that did not impair function. We found no rotational deformity in any patient, nor did we detect joint space narrowing, arthrosis, or chondrolysis (Figure 5).
All K-wires, except for those in one patient, were removed in the outpatient setting. The PS removal was performed during tenolysis in the operating room due to adhesion in three patients in the PS group.

The mean number of images obtained was $3.8 \pm 1.4$ in the PS group and $18.9 \pm 5.1$ in the K-wire group $(\mathrm{p}<0.05)$. The mean duration of surgery was $82.5 \pm 4.1 \mathrm{~min}$ in the PS group and $58.5 \pm 3.5 \mathrm{~min}$ in the K-wire group ( $\mathrm{p}=0.021)$. A significant difference was observed in the mean duration of surgery
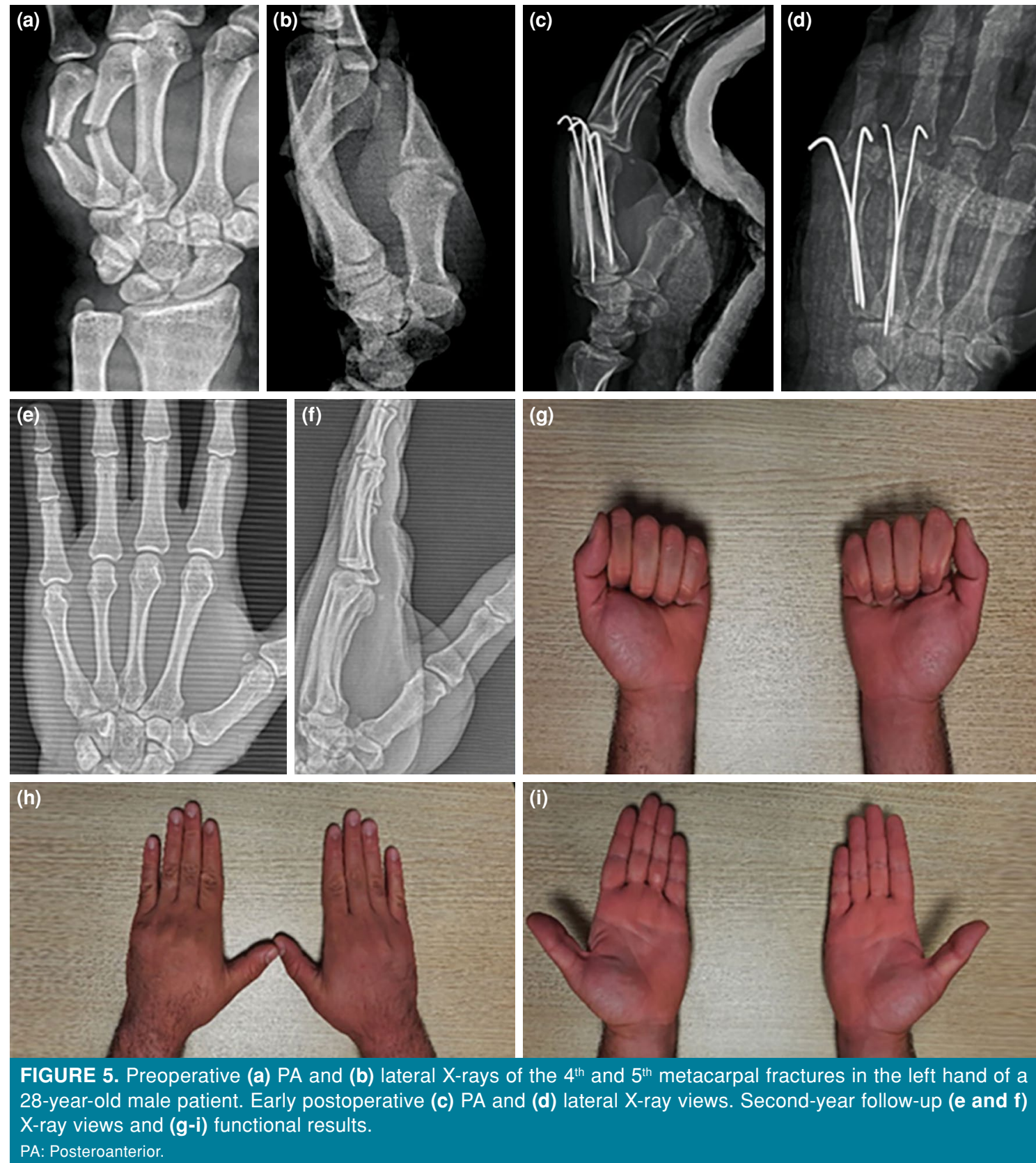

FIGURE 5. Preoperative (a) PA and (b) lateral X-rays of the $4^{\text {th }}$ and $5^{\text {th }}$ metacarpal fractures in the left hand of a 28-year-old male patient. Early postoperative (c) PA and (d) lateral X-ray views. Second-year follow-up (e and f) X-ray views and $(\mathbf{g}-\mathbf{i})$ functional results.

PA: Posteroanterior.
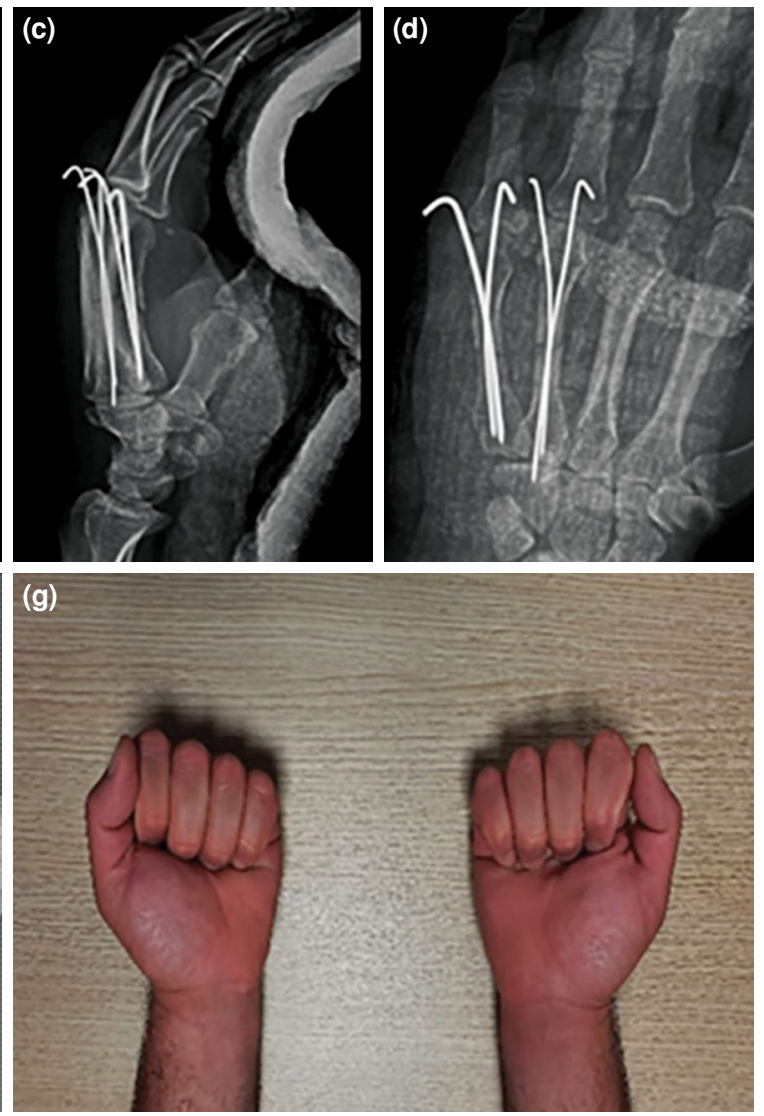
and number of fluoroscopy images between the PS and K-wire groups. In contrast, we found no significant differences in follow-up and union times, total joint AROM, VAS and QuickDASH scores, handgrip strength, postoperative coronal and sagittal angulation, and postoperative shortening between the two groups (Table III).

\section{DISCUSSION}

The optimal surgical treatment for extra-articular metacarpal fractures should shorten surgical time, restrict surgical exposure of fracture sites, and ensure an early return to range of motion (ROM). In our study, we found no significant differences in pain, functional, and QuickDASH scores, as well as reoperation and complication rates, union time, and total joint AROM between the PS and K-wire groups. These findings suggest that both methods can accomplish the primary treatment goal for metacarpal shaft fractures.

Intramedullary K-wire fixation minimally disturbs the extensor tendons and requires a small skin incision, compared to PS fixation. Disadvantages of the wire include intra-articular placement, prevention of early rehabilitation due to lack of sufficient rigidity, pin tract infection, and insufficient rotational stability. ${ }^{[7-9,11]}$ As the wires are introduced intra-articularly, but not through the cartilage, we did not encounter any arthritic changes in the metacarpal head with this method. Retrograde intramedullary $\mathrm{K}$-wire is disadvantageous in comminuted fractures due to the need for additional wires. In addition, the K-wire fixation method required a higher number of fluoroscopic views.

One important disadvantage of the PS fixation is scar formation caused by soft tissue dissection. Also, this procedure may create extensor tendon adhesions or implant irritation. Recent studies have shown that complication rates with both PS and K-wire methods are similar, while functional impairment requiring reoperation is significantly higher in patients undergoing open reduction and internal fixation with a plate, compared to those with percutaneous pinning. ${ }^{[10,12-14]}$

Delicate soft tissue dissection and periosteum repair can reduce adhesions in surgical application with the PS method. Thus, PS fixation reduced secondary surgical intervention for tenolysis and implant extraction. Aykut et al. ${ }^{[15]}$ reported 13\% PS removal rates. In our study, only three patients $(5.8 \%)$ required hardware removal due to tendon irritation and adhesions; tenolysis was performed as a secondary surgical intervention in these patients. We believe that this relatively low rate can be related to the low-profile plates in the dorsal-ulnar direction of the metacarpals and closing the periosteum on the plate. The periosteum with fascial flap (the fascia covering the dorsal interosseous muscle) was used for plate covering to prevent tendon irritation.

According to a study by Hsu et al., ${ }^{[16]}$ no major complications (i.e., osteomyelitis, nonunion, tendon rupture, malunion, infection) were observed in K-wire fixation. Other studies have found that burying the $\mathrm{K}$-wire under the skin reduces the risk of infection; however, burying K-wires requires an operating room to remove the material. ${ }^{[17,18]}$ In our study, one of 37 the patients with a K-wire fixation had a superficial infection. Two of 38 patients in the PS group had an infection, one superficial, and the other deep. Since the K-wires were buried under the skin, pin tract infection and irritation did not possibly develop. Osteomyelitis was not observed in either of the groups. Grafting was performed in two patients in the K-wire group due to nonunion; one of those cases was an open fracture. All fractures united in the PS group.

A study by Lundin et al. ${ }^{[19]}$ showed that PS fixation was more expensive than K-wire fixation. In our study, K-wire was 35 times less expensive than the PS. All $\mathrm{K}$-wires, except for those in one patient, were removed in the outpatient clinic. Secondary interventions that require hospitalization, such as tendon adhesions, nonunion, or malunion, can increase the cost. Two patients with nonunion and one patient requiring implant removal in the K-wire group were reoperated, as well as were three patients with tendon adhesions and implant irritation in the PS group. As these numbers are similar in both groups, the K-wire method stands out due to the implant's lower cost.

Lundin et al. ${ }^{[19]}$ also found that larger ROM was obtained in patients who had PS fixations. Dreyfuss et al. ${ }^{[9]}$ reported obtaining better ROM in patients with PS fixations compared to those with K-wire fixations. According to a meta-analysis in which Melamed et al. ${ }^{[20]}$ compared PS and K-wire fixations, patients undergoing pinning for metacarpal fractures had higher motion scores than open reduction and internal fixation with plate and screws. Functional scores, grip strength, radiographic parameters, time to union, and complications were not significantly different between the two groups. In a biomechanical study, Curtis et al. ${ }^{[21]}$ found that PS fixation was 11 to 15 times stronger than the K-wire fixation. In that study, only one K-wire was used. To support the stability of the K-wire fixation, we used two wires instead of one retrogradely passing through the CMC 
joint. Rotational deformity did not occur in any of our patients. In our study, we encountered similar total joint AROM, as we began ROM in both groups at the same time during the postoperative period.

Taken together, we suggest that the retrograde intramedullary K-wire fixation method is at least as reliable and satisfying as the PS fixation method, and its complications are fewer. Advantages of retrograde intramedullary K-wire fixation are short surgical time, minimally invasive reduction for fracture site (only 6 of 47 fractures were reduced with a mini-open incision), and a second anesthesia in the operating room is not required for implant removal. ${ }^{[22]}$ The main disadvantages include no rigid fixation and excess fluoroscopy views.

Retrospective design is the main limitation of our study. Other limitations include the heterogeneous fracture patterns and different metacarpals being fractured. Further multi-center, large-scale, prospective, randomized-controlled studies with homogeneous fracture patterns can help to develop a standardized algorithm for tailoring the treatment approach.

In conclusion, retrograde intramedullary K-wire fixation has certain advantages such as being less invasive and more accessible with shorter operation time, compared to PS fixation. Similar radiological and clinical scores can be obtained in patients undergoing retrograde intramedullary K-wire fixation or PS fixation.

\section{Declaration of conflicting interests}

The authors declared no conflicts of interest with respect to the authorship and/or publication of this article.

\section{Funding}

The authors received no financial support for the research and/or authorship of this article.

\section{REFERENCES}

1. Chung KC, Spilson SV. The frequency and epidemiology of hand and forearm fractures in the United States. J Hand Surg Am 2001;26:908-15.

2. Diaz-Garcia R, Waljee JF. Current management of metacarpal fractures. Hand Clin 2013;29:507-18.

3. Kamath JB, Harshvardhan, Naik DM, Bansal A. Current concepts in managing fractures of metacarpal and phalangess. Indian J Plast Surg 2011;44:203-11.

4. Ruchelsman DE, Puri S, Feinberg-Zadek N, Leibman MI, Belsky MR. Clinical outcomes of limited-open retrograde intramedullary headless screw fixation of metacarpal fractures. J Hand Surg Am 2014;39:2390-5.

5. Henry MH. Fractures of the proximal phalanx and metacarpals in the hand: Preferred methods of stabilization. J Am Acad Orthop Surg 2008;16:586-95.
6. Melone CP Jr. Rigid fixation of phalangeal and metacarpal fractures. Orthop Clin North Am 1986;17:421-35.

7. Lee SK, Kim KJ, Choy WS. Modified retrograde percutaneous intramedullary multiple Kirschner wire fixation for treatment of unstable displaced metacarpal neck and shaft fractures. Eur J Orthop Surg Traumatol 2013;23:535-43.

8. Winter $M$, Balaguer $T$, Bessière $C$, Carles $M$, Lebreton E. Surgical treatment of the boxer's fracture: Transverse pinning versus intramedullary pinning. J Hand Surg Eur Vol 2007;32:709-13.

9. Dreyfuss D, Allon R, Izacson N, Hutt D. A comparison of locking plates and intramedullary pinning for fixation of metacarpal shaft fractures. Hand (N Y) 2019;14:27-33.

10. Ozer K, Gillani S, Williams A, Peterson SL, Morgan S. Comparison of intramedullary nailing versus plate-screw fixation of extra-articular metacarpal fractures. J Hand Surg Am 2008;33:1724-31.

11. Schädel-Höpfner $M$, Wild $M$, Windolf $J$, Linhart W. Antegrade intramedullary splinting or percutaneous retrograde crossed pinning for displaced neck fractures of the fifth metacarpal? Arch Orthop Trauma Surg 2007;127:435-40.

12. Fusetti C, Meyer H, Borisch N, Stern R, Santa DD, Papaloïzos M. Complications of plate fixation in metacarpal fractures. J Trauma 2002;52:535-9.

13. Page SM, Stern PJ. Complications and range of motion following plate fixation of metacarpal and phalangeal fractures. J Hand Surg Am 1998;23:827-32.

14. Greeven AP, Bezstarosti S, Krijnen P, Schipper IB. Open reduction and internal fixation versus percutaneous transverse Kirschner wire fixation for single, closed second to fifth metacarpal shaft fractures: A systematic review. Eur J Trauma Emerg Surg 2016;42:169-75.

15. Aykut S, Öztürk K, Özcan Ç, Demiroğlu M, Gürün AU, Özden E. Results of surgical treatment in metacarpal shaft fractures using low profile mini plates. Ulus Travma Acil Cerrahi Derg 2015;21:279-84.

16. Hsu LP, Schwartz EG, Kalainov DM, Chen F, Makowiec RL. Complications of k-wire fixation in procedures involving the hand and wrist. J Hand Surg Am 2011;36:610-6.

17. Chitten JJ, Muthaiyan P, James B, Savery VB. Incidence of pin site infection in buried vs unburied k-wire fixation techniques in fracture fixation. JCDR 2018;12:RC01-RC03

18. Ahmad A, Qureshi MA, Ali Z. Pin tract infection rates between percutaneous and buried k-wires in supracondylar fracture of humerus in children. Pak J Surg 2010;26:146-50.

19. Lundin M, Woo E, Hardaway J, et al. The cost of quality: Open reduction and internal fixation techniques versus percutaneous $\mathrm{k}$-wire fixation in the management of extraarticular hand fractures. J Ortho Rehab Surg 2017;1:19-24.

20. Melamed E, Joo L, Lin E, Perretta D, Capo JT. Plate fixation versus percutaneous pinning for unstable metacarpal fractures: A meta-analysis. J Hand Surg Asian Pac 2017;22:29-34.

21. Curtis BD, Fajolu O, Ruff ME, Litsky AS. Fixation of metacarpal shaft fractures: biomechanical comparison of intramedullary nail crossed k-wires and plate-screw constructs. Orthop Surg 2015;7:256-60.

22. Atik OŞ. Is there something new and interesting in my article? Eklem Hastalik Cerrahisi 2019;30:69. 